\title{
Pedigree: A Program to Trace and Draw Pedigree Records
}

\author{
Shahrokh Khanizadeh ${ }^{1}$ \\ Agriculture Canada, 430 Boulevard Gouin, St-Jean-sur-Richelieu, \\ Quebec J3B 3E6, Canada
}

\section{Michel J. Lareau \\ Agriculture Canada, 430 Boulevard Gouin, St-Jean-sur-Richelieu, Quebec J3B 3E6, Canada}

\section{Deborah Buszard Plant Science Department, McGill University, Quebec H9X 1C0, Canada}

Additional index words. breeding, genealogy, family-tree, lineage

Plant breeders are often interested in studying the pedigree of breeding lines and cultivars that have potential as parents in crop improvement. Tracing and drawing pedigrees have generally been performed manually, which is both laborious and timeconsuming.

Breeders have recently had the opportunity to implement a wide range of microcomputer software programs, such as those that analyze linkage and mutation frequency (St. John et al., 1983), structure and genetic variation of populations (Dowling and Moore, 1984), genotype-environment interaction (Kang, 1985), and generation means ( $\mathrm{Ng}$, 1990), as well as those for record keeping and progeny evaluation (Bassi et al., 1990) to improve efficiency in breeding programs. However, until now, no software has been developed to draw a pedigree. We report the application of a user-friendly software program to simplify tracing and drawing of pedigrees.

Pedigree (Khanizadeh, 1990) was developed in the dBASE IV (Ashton-Tate Corp., Torrance, Calif., 1988) language and compiled into an executable program (Extension EXE) using Clipper with Microsoft C Runtime Library Routines (Nantucket Corp., Culver City, Calif., 1987) and dBASE Developer's edition-Runtime (Ashton-Tate, 1988). Pedigree stores information in a dBASE111 or dBASEIV file format. This information can be retrieved and modified by

Received for publication 4 Sept. 1990. Agriculture Canada Contribution no. 335/90.03.03R. We thank Ian Wallace, Agriculture Canada: A. Dale. Ontario Ministry of Agriculture and Food; and A.K. Anderson, Agriculture Canada, Vancouver, B.C., for reviewing and testing the program. The cost of publishing this paper was defrayed in part by the payment of page charges. Under postal regulations, this paper therefore must be hereby marked advertisement solely to indicate this fact. 'Programmer.
Pedigree or the dBASE program. The data base file has 40 fields, including genotype name, female parent, male parent, and common useful characteristics, such as origin, hardiness, disease, color, taste, vigor, etc., plus three additional fields for comments. The naming of these fields can be changed to accommodate any species of interest. At execution, the program displays a main menu and prompts the user for a choice. The program can perform the following commands: 1) add a genotype, 2) modify an existing genotype, 3) delete/recall a genotype, 4) generate a family tree, 5) list options, 6) select a crop, 7) help, and 8) quit. The list option allows the user to search genotypes with common characteristics, such as similarity in parents, or to list all characteristics of a genotype or a group of genotypes. All of the information generated by this program can be listed on the monitor or printed: An additional on-line edit command is added to the program to allow the user to edit a geno- type while displaying a pedigree (option 4). There is no limitation to the number of crosses searched, and the extension of the pedigree tree depends totally on the size of the monitor. Also, a screen dump utility is available for any printer device. If the information for a particular genotype or cultivar is incom-

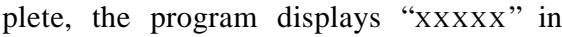
the provided field (Fig. 1).

A disk copy of Pedigree, along with a sample data disk (for which a screen display is shown in Fig. 1) and manual, is available for IBM and compatible machines with a minimum of $640 \mathrm{~K}$ memory equipped with any type of monitor (TTL, CGA, EGA, VGA, etc.) and may be obtained from S.K. for a fee. To accelerate the process of tracing the parents, drawing the pedigree, or searching for a specified genotype, it is recommended that at least a 80286 machine be used for data files having more than 1000 records. Modifications to and enhancement of new versions will be sent to users free of charge.

\section{Literature Cited}

Bassi, D., E. Muzzi, P. Negri, and R. Selli. 1990 A computer program for record-keeping and seedling evaluation in fruit trees. HortScience 25:121.

Dowling, T.E. and X.S. Moore. 1984. A program for estimating genetic variability within and between populations. J. Hered. 75:416.

Kang, M.S. 1985. SAS program for calculating stability-variance parameters. J. Hered. 76:142143.

Khanizadeh, S. 1990. Pedigree, Version 3.0, Registration no. 403061. Consumer and Corporate Affairs Canada, Copyright Office, Ottawa.

Ng, T.J. 1990. Generation means analysis by microcomputer. HortScience 25:363.

St. John, R.C., N. Shafer, and R.C. Woodruff. 1983. A computer analysis of the statistical significance of mutation rates. J. Hered. 74:8587.

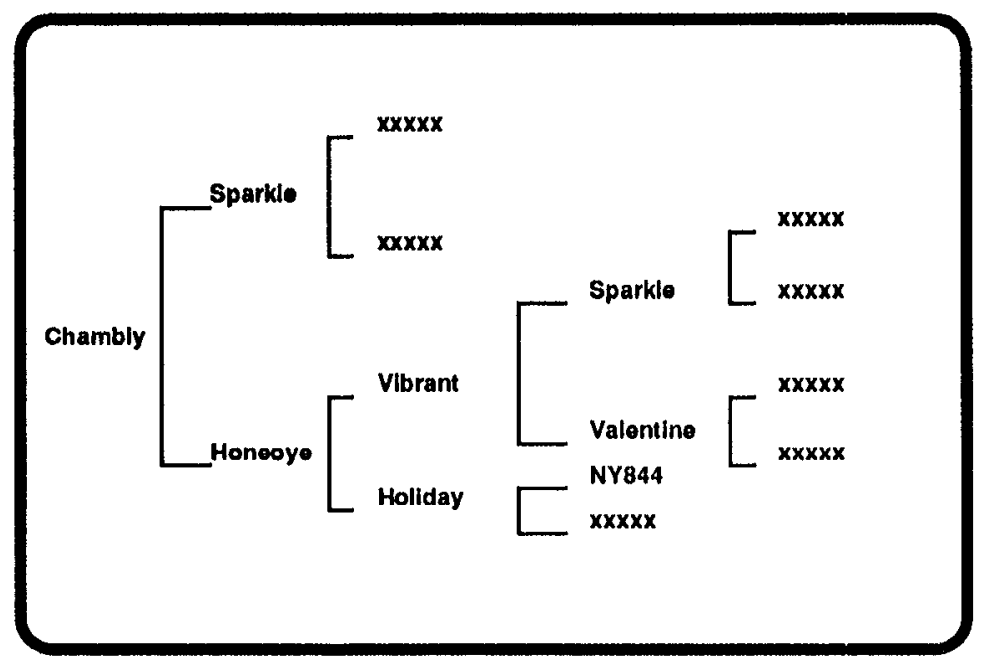

Fig. 1. An example of the screen display after execution of the Pedigree program using a strawberry data base file. 